\title{
Photoacclimation and nutrient-based model of light-saturated photosynthesis for quantifying oceanic primary production
}

\author{
Michael J. Behrenfeld ${ }^{1, *}$, Emilio Marañón ${ }^{2}$, David A. Siegel ${ }^{3}$, Stanford B. Hooker ${ }^{1}$ \\ ${ }^{1}$ National Aeronautics and Space Administration, Goddard Space Flight Center, Code 971, Building 33, Greenbelt, \\ Maryland 20771, USA \\ ${ }^{2}$ Departamento de Ecología y Biología Animal, Universidad de Vigo, 36200 Vigo, Spain \\ ${ }^{3}$ Institute for Computational Earth System Science, University of California Santa Barbara, Santa Barbara, \\ California 93106-3060, USA
}

\begin{abstract}
Availability of remotely sensed phytoplankton biomass fields has greatly advanced primary production modeling efforts. However, conversion of near-surface chlorophyll concentrations to carbon fixation rates has been hindered by uncertainties in modeling light-saturated photosynthesis $\left(P_{\text {max }}^{\mathrm{b}}\right)$. Here, we introduce a physiologically-based model for $P^{\mathrm{b}}{ }_{\max }$ that focuses on the effects of photoacclimation and nutrient limitation on relative changes in cellular chlorophyll and $\mathrm{CO}_{2}$ fixation capacities. This 'PhotoAcc' model describes $P^{\mathrm{b}}{ }_{\max }$ as a function of light level at the bottom of the mixed layer or at the depth of interest below the mixed layer. Nutrient status is assessed from the relationship between mixed layer and nutricline depths. Temperature is assumed to have no direct influence on $P^{\mathrm{b}}{ }_{\max }$ above $5^{\circ} \mathrm{C}$. The PhotoAcc model was parameterized using photosynthesisirradiance observations made from extended transects across the Atlantic Ocean. Model performance was validated independently using time-series observations from the Sargasso Sea. The PhotoAcc model accounted for 70 to $80 \%$ of the variance in light-saturated photosynthesis. Previously described temperature-dependent models did not account for a significant fraction of the variance in $P_{\text {max }}^{\mathrm{b}}$ for our test data sets.
\end{abstract}

KEY WORDS: Photosynthesis $\cdot$ Modeling $\cdot$ Primary production

Resale or republication not permitted without written consent of the publisher

\section{INTRODUCTION}

Photosynthesis is a fundamental process of nearly all known ecosystems, such that the level of photoautotrophic carbon fixation supported by a given environment broadly dictates the local biomass of subsequent trophic levels and the biogeochemical exchange of elements between systems. Models of biospheric primary production have been greatly aided by globalscale satellite observations (Field et al. 1998), but conversion of measured plant biomass to net photosynthe-

*E-mail: mjb@neptune.gsfc.nasa.gov sis has remained problematic. Whereas terrestrial productivity models suffer from a lack of observational data for parameterization and testing (Field et al. 1998), high-sensitivity measurements of net primary production in aquatic systems have been routine since the introduction of the ${ }^{14} \mathrm{C}$ method by Steemann Nielsen (1952).

Analyses of vertical profiles of phytoplankton photosynthesis revealed early on that, when normalized to depth-specific chlorophyll concentrations, primary production can be modeled to first order simply as a function of subsurface irradiance (Ryther 1956, Ryther \& Yentsch 1957, Talling 1957). A variety of analytical expressions have consequently been developed de- 
scribing this relationship between vertical light attenuation and chlorophyll-normalized carbon fixation (reviewed by Platt \& Sathyendranath 1993, Behrenfeld \& Falkowski 1997b). Such models can account for most of the observed variance in depth-integrated photosynthesis ( $(\mathrm{PP})$, particularly when measurements encompass a wide phytoplankton biomass range, provided model input includes measured values for: (1) the vertical distribution of chlorophyll, (2) the downwelling attenuation coefficient $\left(K_{\mathrm{d}}\right)$ for photosynthetically active radiation (PAR), and (3) the maximum carbon fixation rate per unit of chlorophyll $\left(P^{\mathrm{b}}{ }_{\text {opt }}\right)$ (Behrenfeld \& Falkowski 1997a,b).

For over $40 \mathrm{yr}$, developments in phytoplankton primary production models have focused on refining characterizations of the above 3 critical water-column features, with clearly the greatest achievements realized in the description of the underwater light field (e.g. Platt \& Sathyendranath 1988, Morel 1991, Antoine et al. 1996). Progress has also been made in predicting vertical profiles of chlorophyll (Platt \& Sathyendranath 1988, Morel \& Berthon 1989), but models of $P^{\mathrm{b}}$ opt have remained rudimentary and inconsistent (Behrenfeld \& Falkowski 1997b). The importance of accurate $P^{\mathrm{b}}{ }_{\text {opt }}$ estimates cannot be overstated, especially when model performance is evaluated by comparison with pointsource field observations. For globally representative data sets, phytoplankton biomass alone accounts for $<40 \%$ of $\sum$ PP variability, while inclusion of measured $P^{\mathrm{b}}{ }_{\text {opt }}$ values can account for $>80 \%$ of the variance in ¿PP (Balch \& Byrne 1994, Behrenfeld \& Falkowski 1997a). In oligotrophic regions where the range in chlorophyll concentration is further constrained, accurate estimates of $P^{\mathrm{b}}{ }_{\text {opt }}$ are even more critical (Banse \& Yong 1990, Siegel et al. 2000).

The function of $P^{\mathrm{b}}{ }_{\text {opt }}$ models is to capture spatial and temporal changes in assimilation efficiencies (i.e. carbon fixed per unit of chlorophyll) resulting from physiological acclimation to environmental variability. Currently, the 2 principal approaches for estimating $P^{\mathrm{b}}{ }_{\text {opt }}$ in regional- to global-scale models are: (1) to assign fixed, climatological values to biogeographical provinces (Longhurst 1995, Longhurst et al. 1995), and (2) to define predictive relationships between $P^{\mathrm{b}}{ }_{\text {opt }}$ and 1 or more environmental variables (e.g. temperature, nutrient concentration) (Megard 1972, Balch et al. 1992, Antoine et al. 1996, Behrenfeld \& Falkowski 1997a). Both techniques have advantages, but differ in their intended application. For example, the first approach furnishes broad-scale average values for designated regions and is not intended to accurately reproduce the much finer scale physiological variability in ${ }^{14} \mathrm{C}$-uptake rates corresponding to a given day, depth and location. As for the second approach, an effective model should, ideally, provide $P^{\mathrm{b}}{ }_{\text {opt }}$ estimates comparable at this point-source scale of field measurements, but a successful model of this genre has not yet been described.

Here we introduce a model, belonging to this second category, that captures $P^{\mathrm{b}}$ opt variability in natural phytoplankton assemblages. The model largely focuses on changes in $P^{\mathrm{b}}{ }_{\text {opt }}$ resulting from photoacclimation and is thus referred to as the 'PhotoAcc Model', although a nutrient-dependence is also prescribed. In the following section, we describe theconceptual basis and underlying equations of the PhotoAcc model, the field data used for model parameterization and testing, and our approach to assessing nutrient status and photoacclimation irradiances. Model limitations, directions for expansion, and potential avenues for global implementation are addressed in the section 'Discussion'.

\section{METHODS}

The PhotoAcc model is intended to provide estimates of both $P^{\mathrm{b}}{ }_{\text {opt }}$ and $P^{\mathrm{b}}{ }_{\text {max }}$ that are robust to variations in environmental conditions and taxonomic composition. $P^{\mathrm{b}}{ }_{\text {opt }}$ is measured under ambient light conditions during $\sim 6$ to $24 \mathrm{~h}$ in situ or simulated in situ incubations, and is defined as the maximum chlorophyll-normalized carbon fixation in a water column (the superscript ' $b$ ' denotes normalization to chlorophyll) divided by the incubation light period (Wright 1959, Behrenfeld \& Falkowski 1997a). Natural fluctuations in sunlight cause photosynthesis to vary during such incubations, particularly in lightlimited samples deep within the water column. $P^{\mathrm{b}}{ }_{\text {opt}}$, however, is generally observed near the surface where light levels are sufficient to maintain photosynthesis near the light-saturated rate, $P^{\mathrm{b}}{ }_{\max }$. Thus, unless photoinhibition is excessive or ambient PAR is very low, modeling $P^{\mathrm{b}}$ opt is synonymous with modeling near-surface $P^{\mathrm{b}}$ max .

The longer-term incubations described above treat the water column as a compound photosynthetic unit and yield a single $P^{\mathrm{b}}$ opt value for each vertical profile. In contrast, short-term ( 0.5 to $2 \mathrm{~h})$ photosynthesisirradiance (PI) measurements provide unique relationships between light and carbon fixation for each population sampled within a water column. This technique involves exposing phytoplankton from a given depth to a range of constant light intensities. PI measurements provide critical information on depth-dependent changes in $P_{\text {max }}^{\mathrm{b}}$.

PhotoAcc model. The light-saturated rate of photosynthesis is constrained by the capacity of the Calvin cycle reactions $\left(P_{\max }\right)$, which fix $\mathrm{CO}_{2}$ into carbohydrates (Stitt 1986, Sukenik et al. 1987, Orellana \& Perry 
1992). If chlorophyll (chl) concentration is assumed proportional to light absorption, then $P^{\mathrm{b}}{ }_{\text {max }}$ is the ratio of the Calvin cycle capacity to light-harvesting (i.e. $P_{\text {max }}^{\mathrm{b}}=P_{\text {max }} \times \mathrm{chl}^{-1}$ ). Light absorption and electron transport by the photosynthetic light reactions function primarily to supply ATP and NADPH to the Calvin cycle. Thus, parallel changes in chlorophyll and the Calvin cycle can occur without a change in $P^{\mathrm{b}}{ }_{\max }$. Variations in $P^{\mathrm{b}}{ }_{\max }$ result when acclimation to a new growth condition requires a shift in the balance between light harvesting and carbon fixation. Thus, the essential requirement for an effective $P^{\mathrm{b}}{ }_{\text {max }}$ model is a description of how specific environmental factors cause $P_{\max }$ and chlorophyll to change relative to each other.

The PhotoAcc model estimates $P^{\mathrm{b}}$ max by describing separate, light-dependent relationships for $P_{\max }$ and chlorophyll for 3 environmental conditions: (1) nutrient-sufficient growth in the mixed layer, (2) nutrientsufficient growth below the mixed layer, and (3) nutrient-depleted growth above the nutricline. The challenging aspect of this approach is that the underlying relationships are not resolved in the field and are rarely measured in the laboratory. In the field, $P_{\max }$ and chlorophyll are typically measured per unit volume of water, so changes resulting from physiological acclimation cannot be distinguished from changes due to variations in cell abundance. However, since variability in $P^{\mathrm{b}}{ }_{\text {max }}$ is dependent on relative changes in $P_{\max }$ and chlorophyll, parameterization of the PhotoAcc model can be achieved using a qualitative lightchlorophyll relationship from laboratory photoacclimation studies and field $P^{\mathrm{b}}{ }_{\max }$ data.

Laboratory photoacclimation experiments suggest that phytoplankton exhibit a reasonably conserved response to changes in growth irradiance $\left(I_{\mathrm{g}}\right)$. To illustrate, we assembled chlorophyll-irradiance relationships for 23 phytoplankton species from 23 studies described in the literature (Fig. 1). Reported irradiance values were converted to units of mol quanta $\mathrm{m}^{-2} \mathrm{~h}^{-1}$ following Richardson et al. (1983). Data from a given study were binned according to species, photoperiod, and growth temperature, and then each bin was divided by a scalar to yield normalized chlorophyll concentrations ( $\mathrm{chl}_{\text {norm }}$ ) (see Fig. 1 legend). For the 342 observations in our data set, the relationship between $\mathrm{chl}_{\text {norm }}$ and $I_{\mathrm{g}}$ was described by:

$$
\mathrm{chl}_{\text {norm }}=0.036+0.2 \times \mathrm{e}^{-1.1 \times I_{g}}
$$

Eq. (1) expresses cellular chlorophyll as a function of light (Fig. 1). If Calvin cycle capacities (cell ${ }^{-1}$ ) had been simultaneously measured, then the parameters in Eq. (1) could be adjusted to describe light-dependent changes in chlorophyll relative to $P_{\max }$ (i.e. $\mathrm{chl}_{\mathrm{rel}}$ ). Unfortunately, $P_{\max }$ measurements were not made.

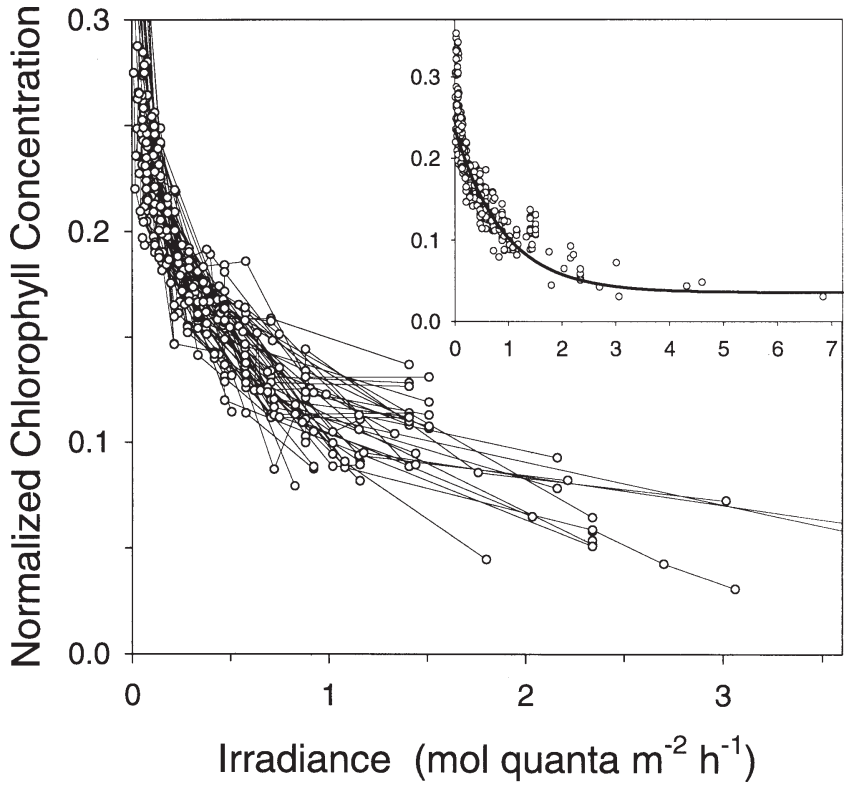

Fig. 1. Compilation of published studies reporting relationships between chlorophyll concentration and growth irradiance $\left(I_{\mathrm{g}}\right)$. Chlorophyll concentrations were divided by a scalar to yield unitless relative values. Scalar values varied primarily as a function of cell size, but were also influenced by factors such as growth temperature, taxonomic division, spectral characteristics of growth irradiance, and units in which chlorophyll concentrations were expressed. These data were compiled to illustrate the general relationship between chlorophyll and $I_{\mathrm{g}}$, but do not represent an exhaustive review of all published results. Inset shows the data without connecting lines, the full scale for $I_{g}$, and the fit (line) of Eq. (1). Irradiance is expressed in units of mol quanta $\mathrm{m}^{-2} \mathrm{~h}^{-1}(3.6 \mathrm{~mol}$ quanta $\mathrm{m}^{-2} \mathrm{~h}^{-1}=1000 \mu \mathrm{mol}$ quanta $\mathrm{m}^{-2} \mathrm{~s}^{-1}$ ). Data sources and species tested were as follows (outliers excluded from figure are identified in parentheses by incubation temperature $\left[{ }^{\circ} \mathrm{C}\right]$, photoperiod [h], and growth irradiance [mol quanta $\left.\mathrm{m}^{-2} \mathrm{~h}^{-1}\right]$ ) - Myers (1946): Chlorella pyrenoidosa; Eppley \& Sloan (1966): Dunaliella tertiolecta (16 h, $0.88 \mathrm{~mol}$ quanta $\left.\mathrm{m}^{-2} \mathrm{~h}^{-1}\right)$; Paasche (1967): Coccolithus huxleyi; Paasche (1968): Ditylum brightwellii $\left(10 \mathrm{~h}, 0.88\right.$ molquanta $\left.\mathrm{m}^{-2} \mathrm{~h}^{-1}\right)$, Nitzschia turgidula; Beale \& Appleman (1971): Chlorella vulgaris; Durbin (1974): Thalassiosira nordenskioldii $\left(5^{\circ} \mathrm{C}, 15 \mathrm{~h}, 0.70\right.$ mol quanta $\mathrm{m}^{-2} \mathrm{~h}^{-1} ; 10^{\circ} \mathrm{C}, 15 \mathrm{~h}, 0.11$ mol quanta $\mathrm{m}^{-2} \mathrm{~h}^{-1} ; 15^{\circ} \mathrm{C}$, $9 \mathrm{~h}, 0.70$ mol quanta $\mathrm{m}^{-2} \mathrm{~h}^{-1}$ ); Beardall \& Morris (1976): Phaeodactylum tricornutum; Chan (1978): Chaetoceros sp., Skeletonema costatum, Cylindrotheca fusiformis, Thalassiosira floridana ( $0.03 \mathrm{~mol}$ quanta $\left.\mathrm{m}^{-2} \mathrm{~h}^{-1}\right)$, Gymnodinium simplex, Amphidinium carterae; Yoder (1979): Skeletonema costatum $\left(22^{\circ} \mathrm{C}, 0.25 \mathrm{~mol}\right.$ quanta $\left.\mathrm{m}^{-2} \mathrm{~h}^{-1}\right)$; Falkowski \& Owens (1980): Skeletonema costatum, Dunaliella tertiolecta; Falkowski (1980): Dunaliella tertiolecta, Skeletonema costatum; Falkowski et al. (1981): Dunaliella tertiolecta; Verity (1981): Leptocylindrus danicus $\left(15^{\circ} \mathrm{C}, 0.23\right.$ mol quanta $\left.\mathrm{m}^{-2} \mathrm{~h}^{-1}\right)$; Cosper (1982a): Skeletonema costatum; Cosper (1982b): Skeetonema costatum; Faust et al. (1982): Prorocentrum mariaelebouriae; Raps et al. (1983): Microcystis aeruginosa; Terry et al. (1983): Phaeodactylum tricornutum; Geider et al. (1985): Phaeodactylum tricornutum; Post et al. (1985): Oscillatoria agardhii; Dubinski et al. (1986): Thalassiosira weisflogii, Isochrysis galbana, Prorocentrum micans; Sukenik et al. (1987): Dunaliella tertiolecta; T. Fisher (unpubl. data): Tetraedron minimum, Nannochloropsis sp. 
However, if $P_{\max }$ exhibits a monotonic dependence on $I_{g}$, then $\mathrm{chl}_{\text {rel }}$ should still follow the relationship:

$$
\mathrm{chl}_{\mathrm{rel}}=a+b \times \mathrm{e}^{-c \times I_{\mathrm{g}}}
$$

For the PhotoAcc model, we assumed that Eq. (2) provides an adequate description of $\mathrm{chl}_{\mathrm{rel}}$. We then derived values for the parameters $(a, b, c)$ using field measurements of $P^{\mathrm{b}}{ }_{\max }$.

For mixed layer, nutrient-sufficient phytoplankton (Condition 1), the PhotoAcc model attributes variability in $P^{\mathrm{b}}{ }_{\text {max }}$ solely to changes in $I_{\mathrm{g}}$. Since chlorophyll is expressed relative to the Calvin cycle capacity, $P_{\max }$ was simply assigned an irradiance-independent value of $1 \mathrm{mgC} \mathrm{m}^{-3} \mathrm{~h}^{-1}$ (Fig. 2a). Light-dependent changes in $\mathrm{chl}_{\text {rel }}$ were then determined by fitting Eq. (2) to the inverse of measured $P^{\mathrm{b}}$ max as a function of $I_{\mathrm{g}}$ (i.e. $\left.\mathrm{chl}_{\text {rel }}=P_{\text {max }} \times P_{\text {max }}^{\mathrm{b}}=1 / P^{\mathrm{b}}{ }_{\text {max }}\right)$, where $I_{\mathrm{g}}$ was taken as the average daily PAR at the bottom of the active mixed layer.

For nutrient-sufficient phytoplankton below the mixed layer (Condition 2), I $I_{g}$ was calculated as the average daily PAR at the depth of interest and $\mathrm{chl}_{\text {rel }}$ was assigned the same relationship with $I_{\mathrm{g}}$ as determined for the mixed layer. Relative to Condition $1, P_{\max }$ was assumed to decrease at very low light below the mixed layer (Fig. 2a: inset) because a high Calvin cycle capacity is unnecessary in chronically light-limited phytoplankton deep within a stratified water column (Geider et al. 1986, Orellana \& Perry 1992). This lightdependent change in $P_{\max }$ was described by:

$$
P_{\max }=d+f \times\left(1-h^{n \times I_{g}}\right)
$$

where $n$ has inverse units of $I_{\mathrm{g}}$ to yield a dimensionless exponent. Parameter values $(d, f, h, n)$ were derived by fitting Eq. (3) to the product of $\mathrm{chl}_{\text {rel }}$ and measured $P^{\mathrm{b}}{ }_{\text {max }}$ as a function of $I_{\mathrm{g}}$.

Few laboratory studies have specifically investigated nutrient-dependent changes in the relative abundance of light harvesting and Calvin cycle components. We assumed that $P^{\mathrm{b}}{ }_{\max }$ would be lower under nutrient-depleted conditions because associated increases in the energetic cost of extracting nutrients from the environment would favor the use of light reaction products for ATP generation rather than carbon fixation. This shift in the balance between light harvesting and carbon fixation was effectuated in the PhotoAcc model by assuming the same light-chl $\mathrm{rel}_{\text {el }}$ relationship as under nutrientsufficient conditions, but a lower, light-independent value for $P_{\max }$ in the mixed layer (Fig. 2b). This nutrientdepleted $P_{\max }$ value was determined by multiplying measured $P^{\mathrm{b}}{ }_{\text {max }}$ and calculated $\mathrm{chl}_{\text {rel }}$ values and taking the median of these products. Between the mixed layer and nutricline, $P_{\max }$ was further reduced as a function of light following the light-dependent relationship derived for nutrient-sufficient cells below the mixed layer
(Fig. 2b: inset). Below the nutricline, $P^{\mathrm{b}}{ }_{\max }$ was estimated using the nutrient-sufficient equations (Fig. 2a).

Parameterizing the PhotoAcc model with field data required an environmental index of nutrient status and an assessment of surface mixing depths. Our approach to these issues and the field data employed are detailed in the 3 subsections that follow the brief model summary below.

To recapitulate: the PhotoAcc model describes lightdependent changes in chlorophyll and $P_{\max }$ for 3 environmental conditions (Fig. 2). For each condition, changes in $P_{\max }$ and $\mathrm{chl}_{\text {rel }}$ are expressed relative to the $P_{\max }$ value of $1 \mathrm{mg} \mathrm{C} \mathrm{m}^{-3} \mathrm{~h}^{-1}$ assigned to nutrientsufficient, mixed-layer phytoplankton. $\mathrm{Chl}_{\mathrm{rel}}$ is assumed to vary with light in a similar manner as chlorophyll per cell, which has been repeatedly measured in the laboratory (Fig. 1). Calvin cycle capacities are not directly measured in the field, so the model is parameterized in a stepwise manner using measurements of $P^{\mathrm{b}}{ }_{\text {max }}$. The

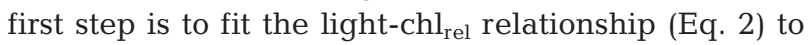
inverse $P^{\mathrm{b}}{ }_{\text {max }}$ values observed in the mixed layer under nutrient-sufficient conditions. Applying this same light-chl $\mathrm{rel}_{\text {rel }}$ relationship to the other 2 conditions allows the remaining $P_{\max }$ equations to be solved. Specifically, the light-dependent change in $P_{\max }$ below the mixed layer (Fig. 2: insets) is determined by fitting Eq. (3) to the product of $\mathrm{chl}_{\text {rel }}$ and measured $P^{\mathrm{b}}{ }_{\text {max }}$ values from below the mixed layer. The lower $P_{\max }$ value for nutrientdepleted conditions (Fig. 2b) is determined as the mean of the products, chl $_{\text {rel }} \times P^{\mathrm{b}}{ }_{\text {max }}$ (where $P^{\mathrm{b}}{ }_{\text {max }}$ values are measured in nutrient-depleted waters).

Field data. The PhotoAcc model was parameterized using Atlantic Meridional Transect (AMT) data. Each AMT field campaign involves a suite of complimentary physical, chemical, and biological observations from a diversity of oceanographic regimes. We employed results from 2 of these program transects, AMT-2 (22 April to 22 May 1996) and AMT-3 (16 September to 25 October 1996) each spanning an $11000 \mathrm{~km}$ region between the United Kingdom and the Falkland Islands. In addition to encompassing 5 of the major biogeochemical provinces defined by Longhurst et al. (1995), these AMT studies were also ideal for model parameterization because they exhibited significantly divergent latitudinal patterns in $P^{\mathrm{b}}{ }_{\text {max }}$ despite being nearly identical geographical transects (Marañón \& Holligan 1999, Marañón et al. 2000).

Protocols employed for optical and biological measurements during AMT-2 and AMT-3 have been previously reported (Robins et al. 1996, Marañón \& Holligan 1999, Marañón et al. 2000). Optical measurements were conducted using the SeaWiFs Optical Profiling System (SeaOPS) with a set of 7-channel light sensors (Robins et al. 1996). Optical measurements with the SeaOPS have a characteristic uncertainty of $3.4 \%$, 

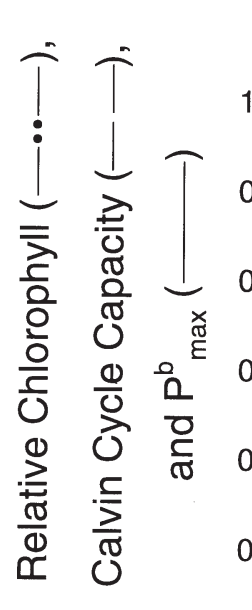

a

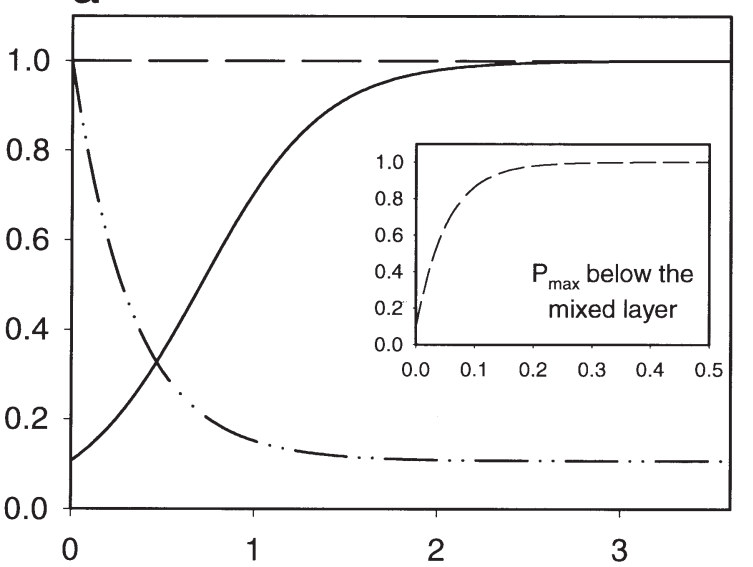

Growth Irradiance b

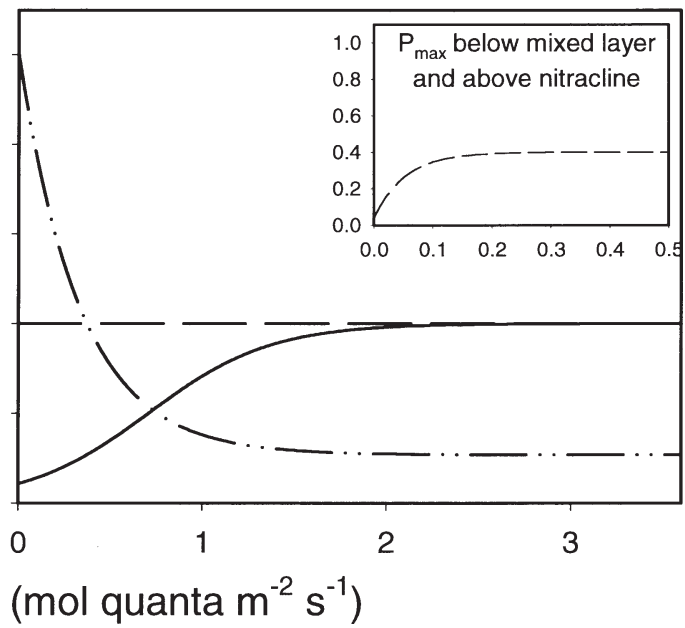

Fig. 2. PhotoAcc model relationships between growth irradiance $\left(I_{\mathrm{g}}\right)$ and chlorophyll concentration, Calvin cycle capacity $\left(P_{\text {max }}\right)$, and chlorophyll-normalized light-saturated photosynthesis $\left(P^{\mathrm{b}}{ }_{\max }\right)$. (a) Nutrient-sufficient conditions; (b) nutrient-depleted conditions. Inset in (a): light-dependent decrease in $P_{\max }$ for nutrient-sufficient growth below the mixed layer; inset in (b): lightdependent decrease in $P_{\max }$ for nutrient-depleted phytoplankton between nitracline and bottom of mixed layer. The lightchlorophyll relationship is the same for all growth conditions and is normalized here to a value of 1 at $I_{\mathrm{g}}=0 \mathrm{molquanta}^{-2} \mathrm{~h}^{-1}$. $P_{\max }$ is expressed relative to a value of $1 \mathrm{mgC} \mathrm{m}^{-3} \mathrm{~h}^{-1}$ for mixed-layer, nutrient-sufficient conditions; $P^{\mathrm{b}}$ max is expressed relative to nutrient-sufficient, high-light conditions

with $1.5 \%$ of this from ship-shadow contamination (Hooker \& Maritorena 2000). Photosynthesis-irradiance measurements were conducted on samples collected at each station from $7 \mathrm{~m}$, near the base of the mixed layer, and near the chlorophyll maximum (Marañón \& Holligan 1999). This sampling strategy provided $P_{\max }^{\mathrm{b}}$ values from within and below the mixed layer. Data collected between 40 and $49^{\circ} \mathrm{N}$ during AMT-2 (3 stations) were not used in our analysis because of inconsistencies in parallel chlorophyll measurements (specifically, the 2 records had similar patterns, but were juxtaposed by 1 station), nor did we use the AMT-3 data from $60 \mathrm{~m}$ at $38^{\circ} \mathrm{S}$ because of a large discrepancy between chlorophyll concentration and spectral attenuation coefficients $\left(K_{\mathrm{d}_{\lambda}}\right)$.

Performance of the PhotoAcc model was additionally tested using a 6 yr record of light and primary production from the US-JGOFS Bermuda Atlantic Time Series (BATS) program and Bermuda BioOptics Program (BBOP). BATS and BBOP measurement protocols have been described previously (Knap et al. 1993, Michaels \& Knap 1996, Siegel et al. 1995a,b, 2000). Chlorophyllnormalized rates of primary production $\left(P^{\mathrm{b}}\right)$ were based on light-dark in situ ${ }^{14} \mathrm{C}$-uptake measurements conducted from sunrise to sunset and HPLC determinations of phytoplankton pigment. Each vertical profile of $P^{\mathrm{b}}$ was visually inspected to extract the appropriate value for $P^{\mathrm{b}}{ }_{\text {opt }}$. With few exceptions, $P^{\mathrm{b}}{ }_{\text {opt }}$ was taken as the $P^{\mathrm{b}}$ value measured at $20 \mathrm{~m}$. Above this depth, a slight photoinhibitory effect was common, while $P^{\mathrm{b}}$ values below
$20 \mathrm{~m}$ generally decreased due to longer periods of lightlimited photosynthesis. On a few occasions, the $P^{\mathrm{b}}$ value at $20 \mathrm{~m}$ greatly exceeded values immediately above and below this depth, in which case the second highest $P^{\mathrm{b}}$ value was taken as $P^{\mathrm{b}}$ opt . Mixed-layer primary production is phosphate-limited at the BATS site during the summer months (Michaels et al. 1994, 1996).

Nutrient limitation index. An environmental index was required to discriminate between nutrient-sufficient and nutrient-depleted water masses. The dissolved concentration of nutrients does not provide an effective index because, over a majority of the open ocean, the daily allocation of resources available for growth is largely determined by food-web recycling rates. We therefore used the relationship between the physical mixed layer depth $\left(Z_{\mathrm{M}}\right)$ and the nitracline depth $\left(Z_{\mathrm{N}}\right)$ as a first-order index of nutrient status. The basis for this index is that when physical forcing (e.g. a storm) deepens the mixed layer such that mixing penetrates the nutricline, the upper water column becomes 'charged' with nutrients and either a close correspondence exists between $Z_{\mathrm{M}}$ and $Z_{\mathrm{N}}$ or nutrients are elevated throughout the water column. When stratification follows, the mixed layer shoals, and $Z_{\mathrm{M}}$ separates from $Z_{\mathrm{N}}$. Simultaneously, recycling inefficiencies export nutrients out of the active biological pool and into particulate refractory and deep-ocean pools (Eppley \& Peterson 1979). If the time scale of these 2 events is similar, then the separation of $Z_{\mathrm{N}}$ and $Z_{\mathrm{M}}$ should function as a correlate to increasing nutrient stress. 
Clearly, conditions will exist when $Z_{\mathrm{N}}>Z_{\mathrm{M}}$, yet recycling is sufficient to transiently maintain phytoplankton in a nutrient-sufficient physiological state. The relationship between $Z_{N}$ and $Z_{M}$ was thus treated as a first-order index to separate nutrient-sufficient from nutrient-depleted data. For this analysis, $Z_{\mathrm{M}}$ was evaluated from vertical profiles of density $\left(\sigma_{t}\right)$ and $Z_{\mathrm{N}}$ was assigned the depth at which $\mathrm{NO}_{3}{ }^{-}$was first detected. For nearly the entire AMT-3 transect, either a close correspondence existed between $Z_{\mathrm{M}}$ and $Z_{\mathrm{N}}$, or $\mathrm{NO}_{3}{ }^{-}$was detectable to the surface (Fig. 3a). The AMT-3 data were thus used to parameterize the nutrient-sufficient PhotoAcc equations (Fig. 2a). During AMT-2, a general separation between $Z_{\mathrm{M}}$ and $Z_{\mathrm{N}}$ was observed from $30^{\circ} \mathrm{N}$ to $42^{\circ} \mathrm{S}$ (Fig. 3b).
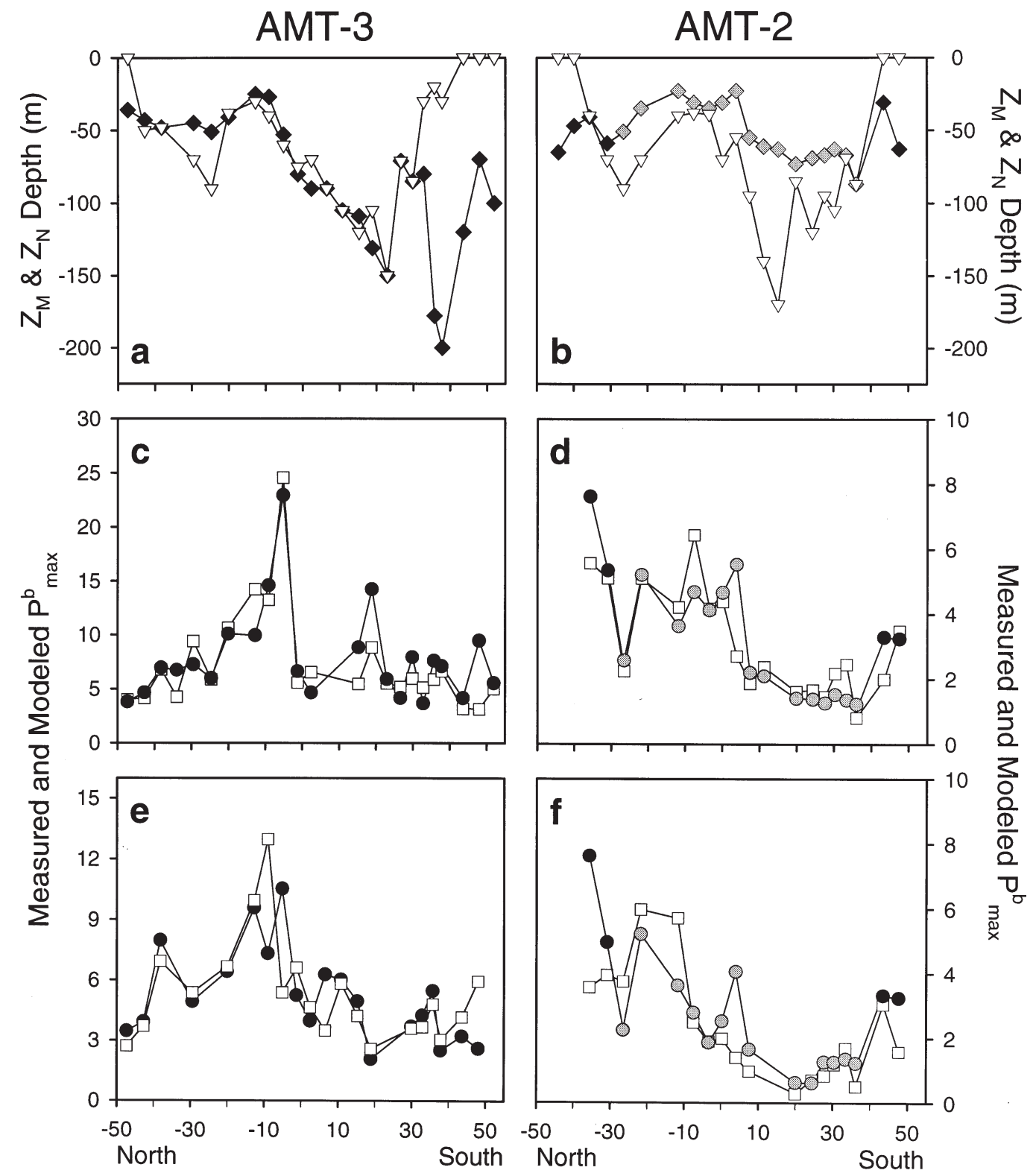

Latitude

Fig. 3. Results for the Atlantic Meridional Transect studies: (a, c, e) AMT-3 and (b, d, f) AMT-2. (a, b) Physical mixed layer $\left(Z_{\mathrm{M}}\right.$ : $\bullet$, $\diamond)$ and nitracline $\left(Z_{\mathrm{N}}: \nabla\right)$ depths; gray symbols identify central section of AMT-2 transect that was treated as nutrient-depleted; $Z_{\mathrm{N}}$ was taken as the depth at which $\mathrm{NO}_{3}{ }^{-}$was first detectable or assigned a value of $0 \mathrm{~m}$ when $\mathrm{NO}_{3}{ }^{-}$was elevated throughout the water column. (c-f) Measured $(\square)$ and modeled $(\bullet, \odot)$ chlorophyll-normalized light-saturated photosynthesis $\left(P^{\mathrm{b}}{ }_{\text {max }}\right.$ : mg $\mathrm{C}$ mg $\left.\mathrm{chl}^{-1} \mathrm{~h}^{-1}\right) ;(\bullet) P^{\mathrm{b}}{ }_{\text {max }}$ estimated using the nutrient-sufficient PhotoAcc model (Fig. 2a); $(\odot) P_{\text {max }}^{\mathrm{b}}$ estimated using the nutrientdepleted PhotoAcc model (Fig. 2b). (c, d) Mixed-layer samples collected at 7 m depth. (e, f) Mid-depth samples collected near $Z_{M}$ 


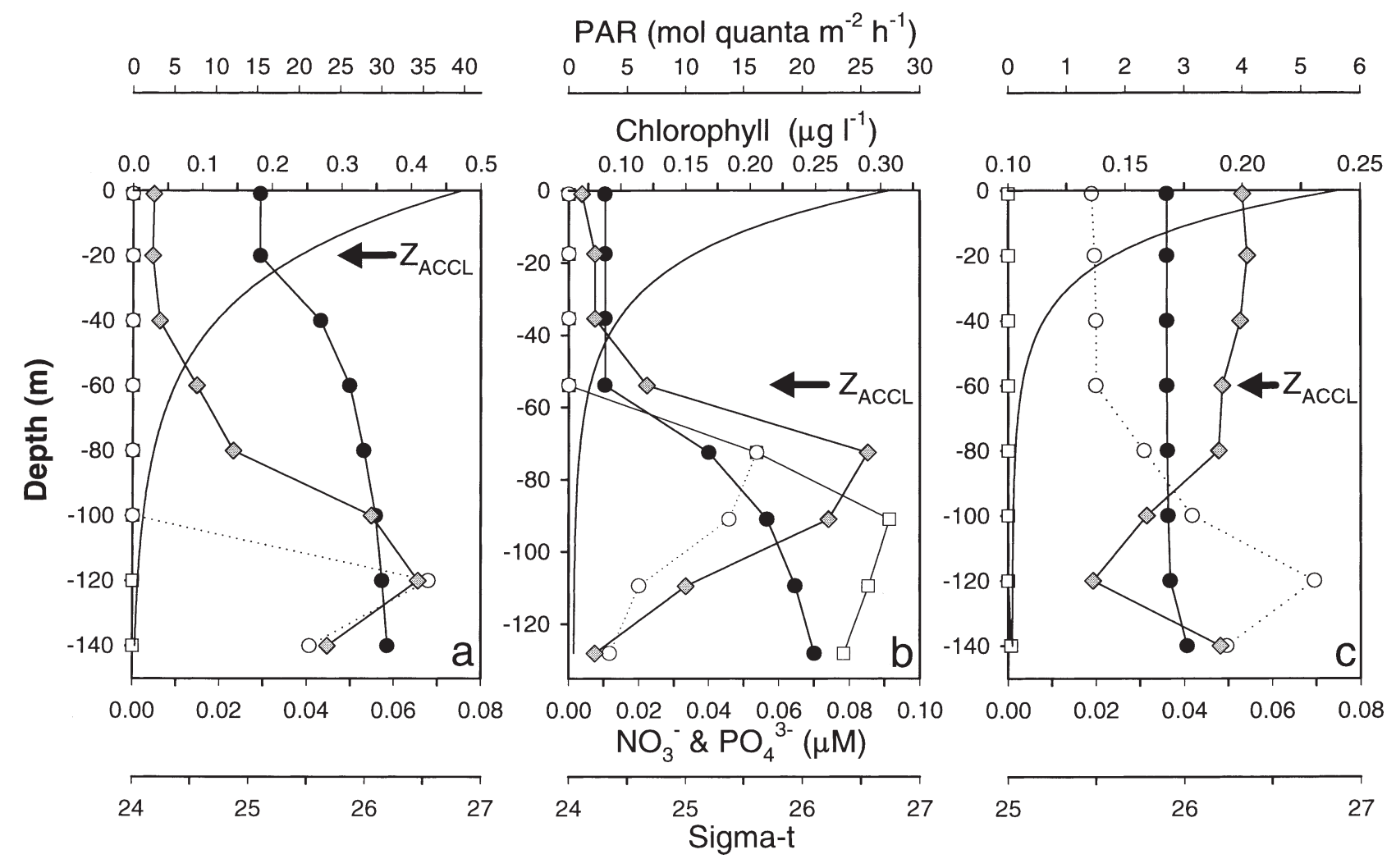

Fig. 4. Exemplary vertical profiles of photosynthetically active radiation (PAR) (—), chlorophyll concentration $(\diamond), \mathrm{NO}_{3}^{-}(\mathrm{O})$, $\mathrm{PO}_{4}{ }^{3-}(\square)$, and sigma-t $\left(\sigma_{\mathrm{t}}: \bullet\right)$ used to identify photoacclimation mixing depths $\left(Z_{\mathrm{ACCL}}: \leftarrow\right)$. (a) Nutrient-depleted water column where $\mathrm{NO}_{3}{ }^{-}$and $\mathrm{PO}_{4}{ }^{3-}$ concentrations are exhausted well below the mixing depth, indicated by $\sigma_{\mathrm{t}}$ in this case, $Z_{\mathrm{ACCL}}$ was taken as the inflection depth in the $\sigma_{\mathrm{t}}$ profile. (b) Typical nutrient 'charged' water column where all profiles indicate a similar depth for $Z_{\mathrm{ACCL}}$. (c) Example of infrequent condition where $\sigma_{\mathrm{t}}$ was vertically uniform but $\mathrm{NO}_{3}{ }^{-}$and chlorophyll profiles indicated shallower mixing; in this case, $Z_{\text {ACCL }}$ was set to the depth indicated by the $\mathrm{NO}_{3}{ }^{-}$profile. These exemplary profiles were extracted

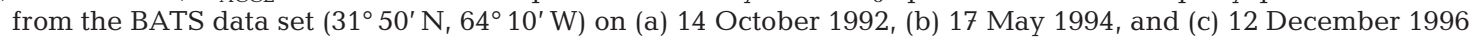

Data from this region were used to parameterize the nutrient-depleted model (Fig. 2b).

Photoacclimation depths. The PhotoAcc model requires an assessment of the mixing depth to which surface phytoplankton are photoacclimated $\left(Z_{\mathrm{ACCL}}\right)$. We determined $Z_{\mathrm{ACCL}}$ by visually inspecting vertical profiles of $\sigma_{\mathrm{t}}, \mathrm{NO}_{3}{ }^{-}, \mathrm{PO}_{4}{ }^{3-}$, and chlorophyll for each sampling date and location, and assigned $Z_{\mathrm{ACCL}}$ the shallowest depth at which a vertical gradient was observed in any of these 4 water-column properties. Invariably, $Z_{\mathrm{ACCL}}$ corresponded to the depth of $Z_{\mathrm{M}}$ under nutrient-depleted conditions (Fig. 4a). Typically, $\sigma_{\mathrm{t}}, \mathrm{NO}_{3}{ }^{-}, \mathrm{PO}_{4}{ }^{3-}$, and chlorophyll all indicated a similar depth for $Z_{\mathrm{ACCL}}$ under nutrient-sufficient conditions (Fig. 4b). However, occasionally when $Z_{\mathrm{M}}$ was large, nutrient and chlorophyll profiles indicated a shallower depth for $Z_{\text {ACCL }}$ than $\sigma_{\mathrm{t}}$ (Fig. 4c). This infrequent condition probably corresponds to a period shortly after a deep mixing event when physical forcing on the system has relinquished and the upper water column is beginning to stratify.

\section{RESULTS}

\section{Parameterized PhotoAcc model}

The first step in model parameterization was to define the light-chl $\mathrm{rel}_{\text {rel }}$ relationship for nutrient-sufficient, mixed-layer phytoplankton (Fig. 2a). This was accomplished by calculating $I_{\mathrm{g}}\left(\mathrm{mol}\right.$ quanta $\mathrm{m}^{-2} \mathrm{~h}^{-1}$ ) at $Z_{\mathrm{ACCL}}$ (m) using measured surface PAR (mol quanta $\mathrm{m}^{-2} \mathrm{~h}^{-1}$ ) and spectral downwelling attenuation coefficients $\left(K_{\mathrm{d}_{\lambda}}\right.$ : $\mathrm{m}^{-1}$ ) and then fitting Eq. (2) to the inverse of mixed layer $P^{\mathrm{b}}{ }_{\max }$ values measured during AMT-3 $\left(\mathrm{r}^{2}=0.62\right)$. The resultant relationship was:

$$
\mathrm{chl}_{\mathrm{rel}}=0.036+0.3 \times \mathrm{e}^{-3 \times I_{\mathrm{g}}}
$$

where the units (from Eq. 2) are: $a=\mathrm{mg} \mathrm{chl} \mathrm{m}^{-3}, b=$ $\mathrm{mgchl} \mathrm{m}^{-3}$, and $c=\mathrm{m}^{2} \mathrm{~h}$ molquanta ${ }^{-1}$.

Eq. (4) was used as the light-chl $\mathrm{rel}_{\text {relationship for }}$ nutrient-sufficient conditions both above and below the mixed layer. The light-dependent relationship for $P_{\max }$ below the mixed layer (Fig. 2a: inset) was para- 
meterized by multiplying $P_{\text {max }}^{\mathrm{b}}$ values measured below $Z_{\mathrm{ACCL}}$ during AMT-3 by calculated $\mathrm{chl}_{\text {rel }}$ values and then fitting Eq. (3) to these products as a function of $I_{\mathrm{g}}\left(\mathrm{r}^{2}=0.72\right)$, where $I_{\mathrm{g}}$ is the average daily PAR at each sampling depth. The resultant relationship was:

$$
P_{\max }=0.1+0.9 \times\left[1-\left(5 \times 10^{-9}\right)^{I_{\mathrm{g}}}\right]
$$

where the units (from Eq. 3) are: $d$ and $f=\mathrm{mg} \mathrm{C} \mathrm{m}^{-3} \mathrm{~h}^{-1}$, $h=$ dimensionless, and $n=1 \mathrm{~m}^{2} \mathrm{~h}$ molquanta ${ }^{-1}$.

For nutrient-depleted conditions, Eq. (4) was again used to describe light-dependent changes in $\mathrm{chl}_{\mathrm{rel}}$. Mixed-layer $P_{\text {max }}^{\mathrm{b}}$ values measured during AMT-2 between $30^{\circ} \mathrm{N}$ and $42^{\circ} \mathrm{S}$ (Fig. $3 \mathrm{~b}$ ) were then multiplied by corresponding values of $\mathrm{chl}_{\mathrm{rel}}$. The median of these products gave a nutrient-depleted value for $P_{\max }$ of $0.40 \mathrm{mgC} \mathrm{m}^{-3} \mathrm{~h}^{-1}\left(\mathrm{SD}=0.15 \mathrm{mgC} \mathrm{m}^{-3} \mathrm{~h}^{-1}\right)$. The additional, light-dependent decrease in $P_{\max }$ between the mixed layer and nutricline (Fig. 2b: inset) was calculated by multiplying $0.40 \mathrm{mg} \mathrm{C} \mathrm{m}^{-3} \mathrm{~h}^{-1}$ by Eq. (5).

In Eqs. (4) \& (5), parameter values were chosen that had the least number of significant digits yet provided a fit to the observational data that was not significantly different from least-squares-derived values. $P^{\mathrm{b}}{ }_{\max }$ is calculated with the PhotoAcc model as the inverse of Eq. (4) for mixed-layer, nutrient-sufficient conditions. Below the mixed layer, $P^{\mathrm{b}}{ }_{\max }$ is calculated as Eq. (5) divided by Eq. (4). Under nutrient-depleted conditions, $P_{\text {max }}^{\mathrm{b}}$ in the mixed layer is calculated as $0.40 \mathrm{mg} \mathrm{C} \mathrm{m}^{-3}$ $\mathrm{h}^{-1}$ divided by Eq. (4), and $P_{\text {max }}^{\mathrm{b}}$ between the mixed layer and nutricline is calculated by multiplying 0.40 $\mathrm{mg} \mathrm{C} \mathrm{m}{ }^{-3} \mathrm{~h}^{-1}$ by Eq. (5), then dividing by Eq. (4).

\section{Model performance}

Comparison of modeled and measured $P^{\mathrm{b}}{ }_{\max }$ values for nutrient-sufficient regions of the AMT transects (black symbols in Fig. 3) indicated that an effective representation of spatial variability in $P^{\mathrm{b}}{ }_{\max }\left(\mathrm{r}^{2}=0.72\right.$, $\mathrm{n}=79$ ) was achieved both above (e.g. Fig. 3c,d) and below (e.g. Fig. 3e,f) $Z_{\mathrm{ACCL}}$. Likewise, the nutrientdepleted model captured spatial variability in $P^{\mathrm{b}}{ }_{\max }$ observed above the nitracline during AMT-2 between $30^{\circ} \mathrm{N}$ and $42^{\circ} \mathrm{S}$ (gray symbols in Fig. $\left.3 \mathrm{~d}, \mathrm{f}\right)\left(\mathrm{r}^{2}=0.71\right.$, $\mathrm{n}=41$ ). Overall, the PhotoAcc model accounted for $76 \%$ of the variance in measured $P^{\mathrm{b}}{ }_{\max }$ for AMT-2 and AMT-3 ( $\mathrm{n}=120)$.

A level of agreement between PhotoAcc estimates of $P^{\mathrm{b}}{ }_{\max }$ and values measured during the AMT studies was anticipated, since the AMT data were used for model parameterization. Performance of the PhotoAcc model was therefore further tested using the independent, 6 yr BATS/BBOP data set (Fig. 5). For these data, a single $P^{\mathrm{b}}{ }_{\text {opt }}$ value was extracted from each monthly profile of $P_{\mathrm{z}}$. The near-surface location of $P^{\mathrm{b}}{ }_{\text {opt }}(\sim 20 \mathrm{~m})$ and minimal photoinhibition ensured that light-saturated photosynthesis $\left(P^{\mathrm{b}}\right.$ max $)$ was maintained during each measurement over most of the photoperiod. $P^{\mathrm{b}}{ }_{\max }$ was calculated for each month using both the nutrient-sufficient and nutrientdepleted models. The nutrient-sufficient model provided the best estimates of $P^{\mathrm{b}}{ }_{\text {opt }}$ during and shortly following the seasonal deep mixing events (black symbols in Fig. 5a), which were evidenced in the profiles of $Z_{\mathrm{M}}$ and $Z_{\mathrm{N}}$ (Fig. 5b). These winter mixing events were followed each year by a period of increasing stratification, whereby $Z_{M}$ gradually separated from $Z_{\mathrm{N}}$ (Fig. 5b). Accordingly, the nutrientdepleted model generally provided the best estimates of $P^{\mathrm{b}}{ }_{\text {opt }}$ during the stratified periods (gray symbols in Fig. 5a). Overall, the PhotoAcc model accounted for $83 \%$ of the variance in $P^{\mathrm{b}}{ }_{\text {opt }}$ for the BATS data set ( $\mathrm{n}=79$ ).

As discussed above in the 'Methods' (subsection 'Nutrient limitation index'), the relationship between $Z_{\mathrm{M}}$ and $Z_{\mathrm{N}}$ simply provides a first-order index of nutrient status. Our model results for the BATS time series (Fig. 5a) clearly indicate that conditions can exist where $Z_{\mathrm{M}}$ and $Z_{\mathrm{N}}$ are separated, yet $P^{\mathrm{b}}$ max exhibits values consistent with the nutrient-sufficient model. Alternative, physiologically-based indices of nutrient status should therefore be investigated. For example, photochemical quantum efficiencies $\left(F_{\mathrm{v}} / F_{\mathrm{m}}\right)$ could provide a useful index and can now be routinely measured using stimulated fluorescence techniques (Kolber \& Falkowski 1993, Falkowski \& Kolber 1995).

\section{Comparison with temperature-dependent $\boldsymbol{P}^{\mathrm{b}}{ }_{\mathrm{opt}}$ models}

Most regional- and global-scale models for $P^{\mathrm{b}}{ }_{\text {opt }}$ are simple functions of sea surface temperature (exceptions by: Balch \& Byrne 1994, Longhurst 1995), with considerable variability between models (Behrenfeld \& Falkowski 1997b). The AMT and BATS studies encompassed a wide range of sea surface temperatures $\left(5^{\circ}\right.$ to $28^{\circ} \mathrm{C}$ ) and thus provided an opportunity to compare the PhotoAcc model with the temperature-dependent models of Megard (1972), Balch et al. (1992), Antoine et al. (1996) and Behrenfeld \& Falkowski (1997a) (Fig. 6). None of these earlier models accounted for more than $9 \%$ of the variance in $P^{\mathrm{b}}{ }_{\max }$ and $P^{\mathrm{b}}{ }_{\text {opt }}$ observed during the AMT and BATS studies ( $\mathrm{n}=199$; Fig. 6a-d). In contrast, the PhotoAcc model accounted for $70 \%$ of the variance when switching between the nutrient-sufficient and nutrient-depleted equations was strictly based on the correspondence between $Z_{\mathrm{M}}$ and $Z_{\mathrm{N}}$ (Fig. 6e). Performance of the PhotoAcc model was improved by $10 \%$ when the best-fit estimates 


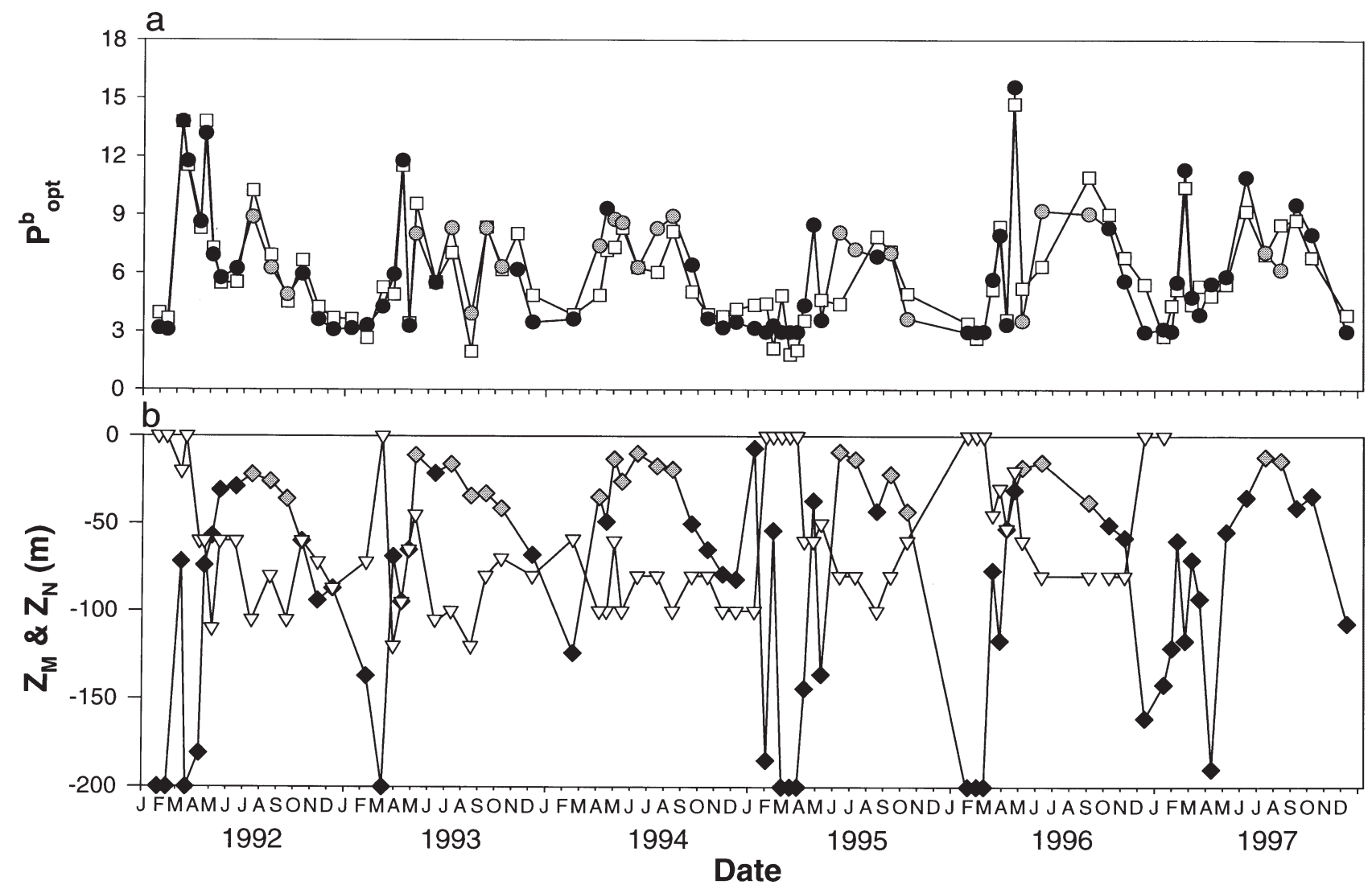

Fig. 5. PhotoAcc results for the 6 yr Bermuda Atlantic Time-Series (BATS) record. (a) Measured ( $\square$ ) and modeled (๑, chlorophyll-normalized carbon fixation $\left(P^{\mathrm{b}}{ }_{\text {opt }}\right.$ : $\left.\mathrm{mg} \mathrm{C} \mathrm{mg} \mathrm{chl}^{-1} \mathrm{~h}^{-1}\right)\left(\mathrm{r}^{2}=0.83\right) ; P^{\mathrm{b}}{ }_{\text {opt }}$ was equated to $P^{\mathrm{b}}{ }_{\text {max }}$ value estimated with the PhotoAcc model; $(\bullet) P^{\mathrm{b}}{ }_{\text {max }}$ estimated using nutrient-sufficient PhotoAcc model (Fig. 2a); $(\odot) P^{\mathrm{b}}{ }_{\max }$ estimated using nutrientdepleted PhotoAcc model (Fig. 2b). (b) Relationship between physical mixed-layer depth $\left.\left(Z_{\mathrm{M}}: \bullet,\right)\right)$ and depth of the nutricline $\left(Z_{\mathrm{N}}: \nabla\right)_{i} Z_{\mathrm{N}}$ was taken as the depth at which $\mathrm{NO}_{3}{ }^{-}$was first detected or assigned a value of $0 \mathrm{~m}$ when $\mathrm{NO}_{3}{ }^{-}$was elevated throughout the water column; $\mathrm{NO}_{3}^{-}$was chosen as an index of nutrient-sufficient or nutrient-depleted conditions rather than $\mathrm{PO}_{4}{ }^{3-}$ because the later was often undetectable even when $Z_{\mathrm{M}}$ was very large; $(\diamond)$ sampling dates when nutrient-sufficient PhotoAcc model yielded best results; $(\diamond)$ sampling dates when nutrient-depleted PhotoAcc model yielded best results

were chosen (Fig. 6f). We conclude from this comparison that: (1) the PhotoAcc model addresses significant sources of variability in $P^{\mathrm{b}}{ }_{\max }$ and $P^{\mathrm{b}}{ }_{\text {opt }}$ that are not adequately captured by simple temperature-dependent functions, and (2) optimal performance of the PhotoAcc model requires replacing our first-order index of nutrient stress with a more quantitative physiological index.

\section{DISCUSSION}

The importance of effectively modeling lightsaturated photosynthesis at the difficult local scale of daily primary production measurements has been recognized for over 40 yr (Ryther 1956, Ryther \& Yentsch 1957). The most common approach to this problem has been to describe $P^{\mathrm{b}}{ }_{\text {opt }}$ as a function of temperature. Such models capture only a fraction of the observed variability in $P^{\mathrm{b}}{ }_{\mathrm{opt}}$, because temperature is weakly cor- related with causative environmental forcing factors. In contrast, the PhotoAcc model attempts to explicitly describe primary causative relationships at the level of chlorophyll synthesis and changes in the Calvin cycle capacity. With this approach, the model effectively reproduced spatial and temporal variability in light-saturated photosynthesis for the AMT and BATS studies. These field programs do not, however, fully encompass global nutrient, light, and temperature conditions. In the following sections, we evaluate the predictions and hypotheses of the PhotoAcc model, discuss potential alterations to account for additional growth constraints, and propose avenues for global implementation.

\section{Maximum light-saturated photosynthesis}

The PhotoAcc model predicts a maximum photosynthetic rate of $P^{\mathrm{b}}{ }_{\max }=1 / 0.036=27.5 \mathrm{mg} \mathrm{chl} \mathrm{m}^{-3}$ (Eq. 4), 
corresponding to nutrient-sufficient, high light conditions. Falkowski (1981) proposed a maximum value of $25 \mathrm{mgC} \mathrm{mg} \mathrm{chl}^{-1} \mathrm{~h}^{-1}$ by assuming a minimum photosynthetic unit $\left(\mathrm{PSU}_{\mathrm{O}_{2}}\right)$ size of 2000 chlorophyll molecules per $\mathrm{O}_{2}$ evolved and a $\mathrm{PSU}_{\mathrm{O}_{2}}$ turnover time $(\tau)$ of $1 \mathrm{~ms}$. Choosing a lower $\mathrm{PSU}_{\mathrm{O}_{2}}$ or $\tau$ value would yield a higher maximum for $P^{\mathrm{b}}{ }_{\max }$. Laboratory measurements suggest that $\mathrm{PSU}_{\mathrm{O}_{2}}$ can range from 300 to 5000 (Falkowski et al. 1981), while $\tau$ may vary from $\geq 5 \mathrm{~ms}$ to slightly less than 2 ms (Falkowski et al. 1981, Behrenfeld et al. 1998) depending on the excess capacity of the photosystems (Kok 1956, Weinbaum et al. 1979, Heber et al. 1988, Leverenz et al. 1990, Behrenfeld et al. 1998). Thus, a potential exists for $P^{\mathrm{b}}{ }_{\max }$ to exceed $25 \mathrm{mgC} \mathrm{mgchl}^{-1} \mathrm{~h}^{-1}$, although values $>20 \mathrm{mgC} \mathrm{mg} \mathrm{chl}^{-1} \mathrm{~h}^{-1}$ are rarely observed in the laboratory (e.g. Glover 1980 reported values between 1.6 and $21 \mathrm{mgC} \mathrm{mg} \mathrm{chl}^{-1} \mathrm{~h}^{-1}$ for 11 species]. In the field, $P^{\mathrm{b}}{ }_{\max }$ (or $P^{\mathrm{b}}{ }_{\text {opt}}$ ) values in excess of $20 \mathrm{mgC} \mathrm{mg} \mathrm{chl}^{-1} \mathrm{~h}^{-1}$ are occasionally reported that exhibit well-defined diurnal patterns (e.g. Malone et al. 1980, Hood et al. 1991). Thus, the PhotoAcc maximum for $P^{\mathrm{b}}{ }_{\max }$ of $27.5 \mathrm{mg} \mathrm{C} \mathrm{mg} \mathrm{chl}^{-1}$ $\mathrm{h}^{-1}$ is (1) close to the theoretical maximum value proposed by Falkowski (1981), (2) well within the range of variability suggested by laboratory measurements of $\mathrm{PSU}_{\mathrm{O}_{2}}$ and $\tau$, and (3) consistent with the maximum $P^{\mathrm{b}}{ }_{\max }$ values reported from previous field studies.

\section{Temperature revisited}

We consider temperature to have a negligible direct influence on $P_{\max }^{\mathrm{b}}$ above $5^{\circ} \mathrm{C}$ for the following reasons:

(1) Laboratory studies with phytoplankton monocultures indicate a clear temperature-dependence for maximum algal growth rates (Eppley 1972), but a variable, species-dependent influence on $P^{\mathrm{b}}$ max (e.g. Steemann Nielsen \& Hansen 1959, Steemann Nielsen \& Jørgensen 1968, Harris 1978, Morris 1981, Post et al. 1985). Enzymatic temperature optima differ between species according to the ambient temperature from which they were isolated. Thus, in field samples with taxonomically diverse phytoplankton assemblages acclimated to their ambient conditions, temperature-dependence of $P^{\mathrm{b}}{ }_{\max }$ is likely to be minimal.

(2) Although the activity of Calvin cycle enzymes, such as ribulose-1-5bisphosphate carboxylase (RuBisCO), exhibits classic Arrhenius temperaturedependence, any decreases in activity at lower temperatures may be offset by increasing enzyme concentrations (Stee-
Fig. 6. Measured $P^{\mathrm{b}}{ }_{\max }$ and $P^{\mathrm{b}}{ }_{\text {opt }}$ values $(\mathrm{n}=199)$ versus modeled values from temperature-dependent functions of (a) Megard (1972) $\left(\mathrm{r}^{2}=0.08\right)$, (b) Balch et Falkowski (1997a) $\left(\mathrm{r}^{2}=0.01\right)$ and the PhotoAcc model when (e) switching between the nutrient-depleted and nutrient-sufficient models was objectively based on the relationship between mixed-layer and nutricline depths $\left(\mathrm{r}^{2}=0.70\right)$ and $(\mathrm{f})$ the best fit from either model was chosen $\left(\mathrm{r}^{2}=0.80\right)$. Observational data are from the Atlantic Meridional Transect studies (AMT-2, AMT-3) and Bermuda Atlantic Time-Series study (BATS). Dashed line indicates 1:1 relationship. Equations for each of the temperature-dependent functions are given in Behrenfeld \& Falkowski (1997b) 
mann Nielsen \& Hansen 1959, Steemann Nielsen \& Jørgensen 1968, Geider et al. 1985, Geider 1987). In other words, sensitivity of $P^{\mathrm{b}}{ }_{\max }$ to temperature may be diminished if increases in enzyme concentration keep pace with decreasing activities at lower temperatures.

(3) Temperature-dependent changes in the Calvin cycle capacity may be paralleled by changes in chlorophyll (e.g. Durbin 1974, Yoder 1979, Verity 1981, Lapointe et al. 1984), such that normalization of $P_{\max }$ to chlorophyll masks temperature dependence.

Below $5^{\circ} \mathrm{C}$, the physiological adjustments described above may not be sufficient to eliminate temperature effects on $P^{\mathrm{b}}{ }_{\text {max }}$. Currently, the minimum mixed-layer $P^{\mathrm{b}}{ }_{\text {max }}$ value predicted by the PhotoAcc model is $3 \mathrm{mgC}$ $\mathrm{mg} \mathrm{chl}^{-1} \mathrm{~h}^{-1}$. This value is near the maximum $P^{\mathrm{b}}$ opt value $\left(<0.5\right.$ to $\sim 3 \mathrm{mgC} \mathrm{mg} \mathrm{chl}^{-1} \mathrm{~h}^{-1}$ ) reported by Dierssen et al. (2000) for Antarctic phytoplankton sampled from -2 to $2^{\circ} \mathrm{C}$ waters. Low $P^{\mathrm{b}}{ }_{\text {opt }}$ values measured in the Southern Ocean partly result from prolonged periods of subsaturated photosynthesis causing a weaker relationship between $P^{\mathrm{b}}{ }_{\text {max }}$ and $P^{\mathrm{b}}{ }_{\text {opt }}$. Nevertheless, a direct temperature effect is likely, and could be accounted for in the PhotoAcc model by treating $P_{\max }$ as a temperature-dependent variable in the nutrient-sufficient model. For example, the following relation (where $T=$ temperature):

$$
P_{\max }=0.4+0.6 \times\left[1-\exp ^{-0.6 \times(T+6)}\right]^{50}
$$

would provide a temperature-dependent decrease in $P^{\mathrm{b}}{ }_{\max }$ below $5^{\circ} \mathrm{C}$ while essentially leaving modeled values above $5^{\circ} \mathrm{C}$ unaltered.

\section{Acclimation irradiance $\left(I_{g}\right)$}

Modeling photoacclimation as a function of light at the bottom of the mixed layer is the simplest formulation mathematically, but its physiological representation is dependent on the kinetic balance between responses to low and high light. Specifically, if photoacclimation follows first-order kinetics with similar rate constants for both high and low light, $P^{\mathrm{b}}$ max will vary as a function of the average light in the mixed layer (Falkowski \& Wirick 1981, Lewis et al. 1984, Cullen \& Lewis 1988). Likewise, $P^{\mathrm{b}}$ max will scale to an irradiance less than the average if responses to low light are stronger (Cullen \& Lewis 1988) and to higher than average light if high-light effects dominate (Vincent et al. 1994, Geider et al. 1996).

Photoacclimation rate constants are typically derived from laboratory 'light-shift' experiments, where cells acclimated for multiple generations to a given irradiance are transferred to much higher or lower light (e.g. Lewis et al. 1984). Riper et al. (1979) suggested that decreases in cellular chlorophyll following a shift to high light result from (1) dilution by coincident cell division and cessation of chlorophyll synthesis, (2) photooxidation, and (3) enzymatic breakdown. If these 3 processes combine to yield a kinetic response of similar magnitude and opposite sign as a shift to low light (Lewis et al. 1984), then phytoplankton acclimate to the average light in the mixed layer by continuously synthesizing and degrading chlorophyll at time scales of $<1 \mathrm{~h}$ as they transit between the surface and $Z_{\mathrm{ACCL}}$.

Light-shift experiments, however, do not mimic natural conditions well, since mixed-layer phytoplankton are preconditioned to periodic high-light exposures and thus are physiologically poised to effectively dissipate excess excitation energy (Behrenfeld et al. 1998). Goericke \& Welschmeyer (1992) demonstrated that chlorophyll turnover is independent of light level in preconditioned cells, and concluded that photooxidation and enzymatic degradation of chlorophyll are artifacts of light-shift experiments. Chlorophyll synthesis at subsaturating light (Escoubas et al. 1995) should thus dominate over the dilution effect of cell division, causing photoacclimation to scale to a lower than average light level. This conclusion implies that cellular chlorophyll changes at the longer time scale of mixed-layer deepening and shoaling. Additional analyses with mixed-layer phytoplankton are clearly needed to better resolve photoacclimation strategies in nature.

\section{Nutrient limitation}

The PhotoAcc model simply switches between nutrient-sufficient and nutrient-depleted equations rather than employing a more gradual transition as a function of nutrient stress. Falkowski et al. (1989) reported a similar switch in the ratio of photosynthetic electron transport (PET) components and RuBisCO for Isochrysis galbana grown under 9 different levels of nitrogen limitation in chemostats. Increasing nutrient stress (i.e. decreasing growth rates) decreased cellular concentrations of all measured components, with a constant stoichiometry for growth rates between 0.59 and $0.96 \mathrm{~d}^{-1}$. At growth rates $<0.59 \mathrm{~d}^{-1}$, the relationship between PET components and RuBisCO abruptly changed by $60 \%$ to a new equilibrium (Fig. 7). The magnitude of this shift is the same as the decrease in $P_{\max }$ used in the nutrient-depleted PhotoAcc model. We are unaware of any physiological explanation for why such an abrupt change occurs, and few laboratory studies have specifically addressed this problem.

Nutrient conditions represented by the AMT and BATS studies included nutrient-sufficient, phosphatedepleted (BATS) (Michaels et al. 1994, 1996), and possibly nitrogen-depleted (AMT-2). We anticipate that 


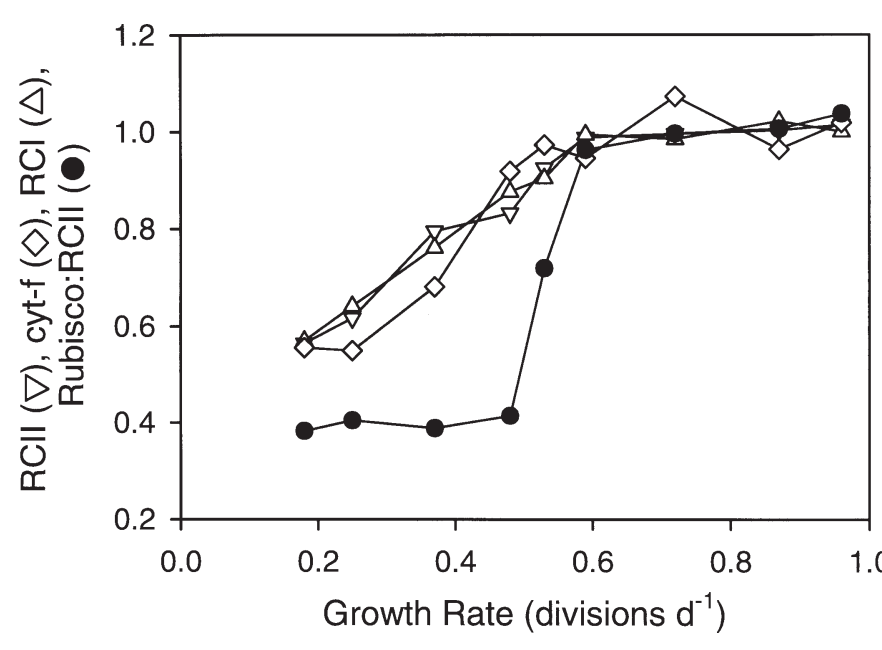

Fig. 7. Isochrysis galbana. Relative changes in photosynthetic electron transport (PET) components and RuBisCO for I. galbana maintained in nitrogen-limited chemostats at growth rates $(\mu)$ ranging from 0.18 to $0.96 \mathrm{~d}^{-1}$. Data are from Table 2 in Falkowski et al. (1989). PET components are: $(\nabla)$ Reaction Center II (RCII), $(\diamond)$ cytochrome-f, and $(\Delta)$ Reaction Center I; ( ) ratio of RCII:RuBisCO. Data are normalized to average value for the 4 highest growth rates. If RuBisCO concentration is assumed proportional to light-saturated carbon fixation $\left(P_{\max }\right)$ (Sukenik et al. 1987), then the decrease in RCII:RuBisCO between $\mu=0.59$ and 0.48 divisions $\mathrm{d}^{-1}$ is of the same magnitude $(60 \%)$ as the decrease in $P_{\max }$ assigned to nutrient-depleted conditions in the PhotoAcc model (Fig. 2b)

an additional set of PhotoAcc equations will be necessary for modeling $P_{\text {max }}^{\mathrm{b}}$ in iron-limited regions. Ironlimitation causes unique stoichiometric changes in the composition of the photosystems, most notably a decrease in cytochrome $b_{6} f$ and a higher Photosystem II to Photosystem I ratio (PSII:PSI) (Guikema \& Sherman 1983, Sandmann 1985, Greene et al.1992, Straus 1994, Vassiliev et al. 1995, Behrenfeld \& Kolber 1999). A high PSII:PSI ratio will diminish chlorophyll-specific efficiencies for converting photochemical energy to the reducing equivalents necessary for carbon fixation, and should thus decrease $P^{\mathrm{b}}{ }_{\max }$ relative to similar levels of growth limitation by nitrogen or phosphate.

\section{Global implementation}

The immediate goal of the research described here was to develop an effective field-based model for $P_{\text {max. }}^{\mathrm{b}}$ Our broader objective, however, is to establish a robust $P^{\mathrm{b}}{ }_{\text {opt }}$ algorithm for estimating global oceanic primary production from satellite ocean-color data. Implementing the PhotoAcc model will require temporally resolved mixed-layer depth and nutrientdepletion fields. As an initial attempt, monthly climatological fields can be assembled from historical data sets (e.g. US National Oceanographic Data Center, Silver Spring, MD), but eventually data coincident with satellite ocean-color measurements will be preferred. Coupled ocean models that assimilate satellite observational data (e.g. surface wind) could be used to generate mixed-layer depth fields. Alternatively, remote-sensing technologies may soon permit global surveys of surface mixing depths, and research is now underway investigating potential lidar techniques for such measurements. Combining remotely sensed seasurface temperature fields with nutrient-depletion/ temperature relationships may prove useful for assessing temporal changes in nutrient status. Again, coupled ocean models may represent an alternative technique. A variety of approaches may therefore be explored for implementing the PhotoAcc model, and each presents an exciting challenge for future research.

\section{Perspective}

Deciphering decadal-scale changes in oceanic primary production from the much larger amplitude signals of seasonal and interannual variability requires foremost a long-term commitment to remote-sensing programs monitoring changes in plant biomass, as well as process-oriented models of depth-dependent changes in phytoplankton biomass and assimilation efficiencies. An evolution from empirical to analytical models of phytoplankton photosynthesis has been realized primarily in the spectral description of the underwater light field (e.g. Platt \& Sathyendranath 1988, Morel 1991, Platt et al. 1991, Antoine et al. 1996). Demonstrable improvements in model performance from these achievements have, unfortunately, been masked by the overwhelming influence of ineffective local-scale models of physiological variability (Balch et al. 1992, Behrenfeld \& Falkowski 1997a,b, Siegel et al. 2000). The PhotoAcc model presented here provides a framework for future improvements in the analytical characterization of physiological variability and, based on comparisons with AMT and BATS data, already incorporates 2 critical forcing factors: light and nutrients.

The importance of environmental physical-chemical variability to physiological traits of algae is well illustrated in the BATS data by the correspondence between changes in $P^{\mathrm{b}}{ }_{\text {opt }}$ and the temporal rhythm of seasonal mixing and stratification (Fig. 5). Nutrient availability at this site clearly influences light-saturated photosynthesis at the seasonal scale, while higher frequency variations in $P^{\mathrm{b}}$ opt are dominated by photoacclimation responses to changes in the mixed-layer depth, surface PAR, and phytoplankton biomass (due 
to associated changes in vertical light attenuation). The BATS data also suggest a significance in the recent history of a water column, as occasional midsummer switches between nutrient-depleted and nutrient-sufficient $P^{\mathrm{b}}$ opt values conceivably reflect the passing of a mesoscale eddy with a significantly different history than the water masses sampled the month before and the month after.

The conceptual basis of our PhotoAcc model entails a variety of hypotheses regarding sources of variability in light-saturated, chlorophyll-normalized photosynthesis. These include a dominant kinetic response to low-light over high-light exposure, an irradiancedependence of the Calvin cycle capacity under chronic low-light conditions, a nutrient-dependent switch in the stoichiometric balance between light-harvesting and Calvin cycle components, and a temperatureindependence of $P^{\mathrm{b}}$ max above $5^{\circ} \mathrm{C}$ in natural phytoplankton assemblages. Additional field and laboratory studies will be necessary to test these hypotheses and to expand the PhotoAcc model to encompass ironlimiting conditions, temperature effects at $<5^{\circ} \mathrm{C}$, and possibly species-dependent variability in phytoplankton pigment composition.

Acknowledgements. M.J.B. thanks John Chapman, Ricardo Letelier, Paul Falkowski, Richard Geider, and Zbigniew Kolber for helpful discussions and inspiration, Elizabeth Stanley for encouragement, and the US National Aeronautics and Space Administration (NASA) (Grant UPN161-35-05- 08) for its continued support. BATS data were assembled by Toby Westberry and Margaret O'Brien. The US JGOFS BATS program is supported by the US National Science Foundation. D.A.S's contributions were supported by NASA. E.M. thanks Manuel Varela and Beatriz Mouriño for assistance during the AMT studies and Alan Pomroy, Colin Griffiths and Malcolm Woodward for providing nutrient data. S.B.H. thanks J. Brown, C. Dempsey, S. Maritorena, and G. Moore for AMT support and J. Aiken for his diligence and commitment to supporting high-quality AMT optical data.

\section{LITERATURE CITED}

Antoine D, André JM, Morel A (1996) Oceanic primary production 2. Estimation at global scale from satellite (coastal zone color scanner) chlorophyll. Global Biogeochem Cycles 10:57-69

Balch WM, Byrne CF (1994) Factors affecting the estimate of primary production from space. J Geophys Res 99(C4): 7555-7570

Balch W, Evans R, Brown J, Feldman G, McClain C, Esaias W (1992) The remote sensing of ocean primary productivity: use of new data compilation to test satellite models. J Geophys Res 97(C2):2279-2293

Banse K, Yong M (1990) Sources of variability in satellitederived estimates of phytoplankton production in the Eastern Tropical Pacific. J Geophys Res 95(C5):7201-7215

Beale SI, Appleman D (1971) Chlorophyll synthesis in Chlorella: regulation by degree of light limitation of growth. Plant Physiol (Wash DC) 47:230-235
Beardall J, Morris I (1976) The concept of light intensity adaptation in marine phytoplankton: some experiments with Phaeodactylum tricornutum. Mar Biol 37:377-387

Behrenfeld MJ, Falkowski PG (1997a) Photosynthetic rates derived from satellite-based chlorophyll concentration. Limnol Oceanogr 42:1-20

Behrenfeld MJ, Falkowski PG (1997b) A consumer's guide to phytoplankton primary productivity models. Limnol Oceanogr 42:1479-1491

Behrenfeld MJ, Kolber ZS (1999) Widespread iron limitation of phytoplankton in the south Pacific Ocean. Science 283: 840-843

Behrenfeld MJ, Prasil O, Kolber ZS, Babin M, Falkowski PG (1998) Compensatory changes in photosystem II electron turnover rates protect photosynthesis from photoinhibition. Photosynth Res 58:259-268

Chan AT (1978) Comparative physiological study of marine diatoms and dinoflagellates in relation to irradiance and cell size. I. Growth under continuous light. J Phycol 14: 396-402

Cosper E (1982a) Effects of variations in light intensity on the efficiency of growth of Skeletonema costatum (Bacillariophyceae) in a cyclostat. J Phycol 18:360-368

Cosper E (1982b) Influence of light intensity on diel variation in rates of growth, respiration, and organic release of a marine diatom: comparison of diurnally constant and fluctuating light. J Plankton Res 4:705-724

Cullen JJ, Lewis MR (1988) The kinetics of algal photoacclimation in the context of vertical mixing. J Plankton Res 10: 1039-1063

Dierssen HM, Vernet M, Smith RC (2000) Optimizing models for remotely estimating primary production in Antarctic coastal waters. Antarct Sci 12:20-32

Dubinsky Z, Falkowski PG, Wyman K (1986) Light harvesting and utilization by phytoplankton. Plant Cell Physiol 27: 1335-1349

Durbin EG (1974) Studies on the autecology of the marine diatom Thalassiosira nordenskiöldii Cleve: I. The influence of daylength, light intensity, and temperature on growth. J Phycol 10:220-225

Eppley RW (1972) Temperature and phytoplankton growth in the sea. Fish Bull 70:1063-1085

Eppley RW, Peterson BJ (1979) Particulate organic matter flux and planktonic new production in the deep ocean. Nature 282:677-680

Eppley RW, Sloan PR (1966) Growth rate of marine phytoplankton: correlations with light absorption by cell chlorophyll. Physiol Plant 19:47-59

Escoubas JM, Lomas M, LaRoche J, Falkowski PG (1995) Light intensity regulation of cab gene transcription is signaled by the redox state of the plastoquinone pool. Proc Natl Acad Sci USA 92:10237-10241

Falkowski PG (1980) Light-shade adaptation in marine phytoplankton. In: Falkowski PG (ed) Primary production in the sea. Plenum Publising Corporation, New York, p 99-119

Falkowski PG (1981) Light-shade adaptation and assimilation numbers. J Plankton Res 3:203-216

Falkowski PG, Kolber Z (1995) Variations in chlorophyll fluorescence yields in phytoplankton in the world oceans. Aust J Plant Physiol 22:341-355

Falkowski PG, Owens TG (1980) Light-shade adaptation. Plant Physiol 66:592-595

Falkowski PG, Wirick CD (1981) A simulation model of the effects of vertical mixing on primary production. Mar Biol 65:69-75

Falkowski PG, Owens TG, Ley AC, Mauzerall DC (1981) Effects of growth irradiance levels on the ratio of reaction 
centers in two species of marine phytoplankton. Plant Physiol 68:969-973

Falkowski PG, Sukenik A, Herzig R (1989) Nitrogen limitation in Isochrysis galbana (Haptophyceae). II. Relative abundance of chloroplast proteins. J Phycol 25:471-478

Faust MA, Sager JC, Meeson BW (1982) Response of Prorocentrum mariae-lebouriae (Dinophyceae) to light of different spectral qualities and irradiances: growth and pigmentation. J Phycol 18:349-356

Field CB, Behrenfeld MJ, Randerson JT, Falkowski PG (1998) Primary production of the biosphere: integrating terrestrial and oceanic components. Science 281:237-240

Geider RJ (1987) Light and temperature dependence of the carbon to chlorophyll ratio in microalgae and cyanobacteria: implications for physiology and growth of phytoplankton. New Phytol 106:1-34

Geider RJ, Osborne BA, Raven JA (1985) Light dependence of growth and photosynthesis in Phaeodactylum tricornutum (Bacillariophyceae). J Phycol 21:609-619

Geider RJ, Osborne BA, Raven JA (1986) Growth, photosynthesis and maintenance metabolic cost in the diatom Phaeodactylum tricornutum at very low light levels. J Phycol 22: $39-48$

Geider RJ, MacIntyre HL, Kana TM (1996) A dynamic model of photoadaptation in phytoplankton. Limnol Oceanogr 41:1-15

Glover HE (1980) Assimilation numbers in cultures of marine phytoplankton. J Plankton Res 2:69-79

Goericke R, Welschmeyer NA (1992) Pigment turnover in the marine diatom Thalassiosira weisflogii. I. The ${ }^{14} \mathrm{CO}_{2}$ labeling kinetics of chlorophyll. J Phycol 28:498-507

Greene RM, Geider RJ, Kolber Z, Falkowski PG (1992) Ironinduced changes in light harvesting and photochemical energy conversion processes in eukaryotic marine algae. Plant Physiol 100:565-575

Guikema JA, Sherman LA (1983) Organization and function of chlorophyll in membranes of cyanobacteria during iron starvation. Plant Physiol 73:250-256

Harris GP (1978) Photosynthesis, productivity, and growth: the physiological ecology of phytoplankton. Arch Hydrobiol Spec Issues (Ergeb Limnol) 10:1-171

Heber U, Neimanis S, Dietz KJ (1988) Fractional control of photosynthesis by the $Q_{B}$ protein, the cytochrome $f / b_{6}$ complex and other components of the photosynthetic apparatus. Planta (Berlin) 173:267-274

Hood RR, Abbott MR, Huyer A (1991) Phytoplankton and photosynthetic light response in the coastal transition zone of northern California in June 1987. J Geophys Res 96: $14769-14780$

Hooker SB, Maritorena S (2000) An evaluation of oceanographic optical instruments and deployment methodologies. J Atmos Oceanic Techol 17:811-830

Knap AH and 11 others (1993) BATS methods - March 1993, BATS method manual, version 3. US JGOFS Planning and Coordination Office, Woods Hole, MA

Kok B (1956) On the inhibition of photosynthesis by intense light. Biochim Biophys Acta 21:234-244

Kolber Z, Falkowski PG (1993) Use of active fluorescence to estimate phytoplankton photosynthesis in situ. Limnol Oceanogr 38:1646-1665

Lapointe BE, Dawes CJ, Tenore KR (1984) Interactions between light and temperature on the physiological ecology of Gracilaria tikvahiae (Gigartinales: Rhodophyta). II. Nitrate uptake and levels of pigments and chemical constituents. Mar Biol 80:171-178

Leverenz JW, Falk S, Pilström CM, Samuelsson G (1990) The effects of photoinhibition on the photosynthetic light- response curve of green plant cells (Chlamydomonas reinhardtii). Planta 182:161-168

Lewis MR, Cullen JJ, Platt T (1984) Relationship between vertical mixing and photoadaptation of phytoplankton: similarity criteria. Mar Ecol Prog Ser 15:141-149

Longhurst A (1995) Seasonal cycles of pelagic production and consumption. Prog Oceanogr 36:77-167

Longhurst A, Sathyendranath S, Platt T, Caverhill C (1995) An estimate of global primary production in the ocean from satellite radiometer data. J Plankton Res 17:1245-1271

Malone TC, Garside C, Neale PJ (1980) Effects of silicate depletion on photosynthesis by diatoms in the plume of the Hudson River. Mar Biol 58:197-204

Marañón E, Holligan PM (1999) Photosynthetic parameters of phytoplankton from $50^{\circ} \mathrm{N}$ to $50^{\circ} \mathrm{S}$ in the Atlantic Ocean. Mar Ecol Prog Ser 176:191-203

Marañón E, Holligan PM, Varela M, Mouriño B, Bale A (2000) Basin-scale variability of phytoplankton biomass, production, and growth in the Atlantic Ocean. Deep-Sea Res Part I 47:825-857

Megard RO (1972) Phytoplankton, photosynthesis, and phosphorus in Lake Minnetonka, Minnesota. Limnol Oceanogr 17:68-87

Michaels AF, Knap AH (1996) Overview of the U.S. JGOFS Bermuda Atlantic time-series study and the Hydrostation S program. Deep-Sea Res Part II 43:157-198

Michaels AF, Knap AH, Dow RL, Gundersen K and 8 others (1994) Seasonal patterns of ocean biogeochemistry at the United States JGOFS Bermuda Atlantic time-series study site. Deep-Sea Res Part I 41:1013-1038

Michaels AF, Olson D, Sarmiento JL, Ammerman JW and 5 others (1996) Inputs, losses, and transformations of nitrogen and phosphorous in the pelagic north Atlantic Ocean. Biogeochemistry 35:181-226

Morel A (1991) Light and marine photosynthesis: a spectral model with geochemical and climatological implications. Prog Oceanogr 26:263-306

Morel A, Berthon JF (1989) Surface pigments, algal biomass profiles, and potential production of the euphotic layer: relationships reinvestigated in view of remote-sensing applications. Limnol Oceanogr 34:1545-1562

Morris I (1981) Photosynthetic products, physiological state, and phytoplankton growth. Can Bull Fish Aquat Sci 210: 83-102

Myers J (1946) Culture conditions and the development of the photosynthetic mechanism. J Gen Physiol 29:419-427

Orellana MV, Perry MJ (1992) An immunoprobe to measure Rubisco concentrations and maximal photosynthetic rates of individual phytoplankton cells. Limnol Oceanogr 37: $478-490$

Paasche E (1967) Marine plankton algae grown with lightdark cycles. I. Coccolithus huxleyi. Physiol Plant 20: 946-956

Paasche E (1968) Marine plankton algae grown with lightdark cycles. II. Ditylum brightwellii and Nitzschia turgidula. Physiol Plant 21:66-77

Platt T, Sathyendranath S (1988) Oceanic primary production: estimation by remote sensing at local and regional scales. Science 241:1613-1620

Platt T, Sathyendranath S (1993) Estimators of primary production for interpretation of remotely sensed data on ocean color. J Geophys Res 98:14561-14567

Platt T, Caverhill C, Sathyendranath S (1991) Basin-scale estimates of oceanic primary production by remote sensing: the North Atlantic. J Geophys Res 96:15147-15159

Post AF, deWit R, Mur LR (1985) Interaction between temperature and light intensity on growth and photosynthesis of 
the cyanobacterium Oscillatoria agardhii. J Plankton Res $7: 487-495$

Raps S, Wyman K, Siegelman HW, Falkowski PG (1983) Adaptation of the cyanobacterium Microcystis aeruginosa to light intensity. Plant Physiol 72:829-832

Richardson K, Beardall J, Raven JA (1983) Adaptation of unicellular algae to irradiance: an analysis of strategies. New Phytol 93:157-191

Riper DM, Owens TG, Falkowski PG (1979) Chlorophyll turnover in Skeletonema costatum, a marine plankton diatom. Plant Physiol 64:49-54

Robins DB, Bale AJ, Moore GF, Rees NW and 6 others (1996) AMT-1 cruise report and preliminary results. In: Hooker SB, Firestone ER (eds) NASA Tech Memo 104566, Vol 35. NASA Goddard Space Flight Center, Greenbelt, MD

Ryther JH (1956) Photosynthesis in the ocean as a function of light intensity. Limnol Oceanogr 1:61-70

Ryther JH, Yentsch CS (1957) The estimation of phytoplankton production in the ocean from chlorophyll and light data. Limnol Oceanogr 2:281-286

Sandmann G (1985) Consequences of iron deficiency on photosynthetic and respiratory electron transport in bluegreen algae. Photosynth Res 6:261-271

Siegel DA, Michaels AF, Sørensen J, O'Brien MC, Hammer MA (1995a) Seasonal variability of light availability and its utilization in the Sargasso Sea. J Geophys Res 100: 8695-8713

Siegel DA, O'Brien MC, Sørensen JC, Konnoff D, Fields E (1995b) BBOP data processing and sampling procedures. US JGOFS Planning Rep No 19, US JGOFS Planning and Coordination Office, Woods Hole, MA

Siegel DA, Westberry TK, O'Brien MC, Nelson NB and 10 others (2000) Bio-optical modeling of primary production on regional scales: the Bermuda biooptics project. DeepSea Res Part II 48:1865-1896

Steemann Nielsen E (1952) The use of radio-active carbon $\left(\mathrm{C}^{14}\right)$ for measuring organic production in the sea. J Cons Int Explor Mer 18:117-140

Steemann Nielsen E, Hansen VK (1959) Light adaptation in marine phytoplankton populations and its interrelation with temperature. Physiol Plant 12:353-370

Editorial responsibility: Otto Kinne (Editor), Oldendorf/Luhe, Germany
Steemann Nielsen E, Jørgensen EG (1968) The adaptation of plankton algae. I. General part. Physiol Plant 21:401-413

Stitt M (1986) Limitation of photosynthesis by carbon metabolism, I. Evidence for excess electron transport capacity in leaves carrying out photosynthesis in saturating light and $\mathrm{CO}_{2}$. Plant Physiol 81:1115-1122

Straus NA (1994) Iron deprivation: physiology and gene regulation. In: Bryant DA (ed) The molecular biology of cyanobacteria. Kluwer Academic, New York, p 731-750

Sukenik A, Bennett J, Falkowski PG (1987) Light-saturated photosynthesis-limitation by electron transport or carbon fixation? Biochim Biophys Acta 891:205-215

Talling JF (1957) The phytoplankton population as a compound photosynthetic system. New Phytol 56:133-149

Terry KL, Hirata J, Laws EA (1983) Light-limited growth of two strains of the marine diatom Phaeodactylum tricornutum Bohlin: chemical composition, carbon partitioning, and the diel periodicity of physiological processes. J Exp Mar Biol Ecol 68:209-227

Vassiliev IR, Kolber Z, Wyman KD, Mauzerall D, Shukla VK, Falkowski PG (1995) Effects of iron limitation on photosystem II composition and light utilization in Dunaliella tertiolecta. Plant Physiol 109:963-972

Verity PG (1981) Effects of temperature, irradiance, and daylength on the marine diatom Leptocylindrus danicus Cleve: I. Photosynthesis and cellular composition. J Exp Mar Biol Ecol 55:79-91

Vincent WF, Bertrand N, Frenette JF (1994) Photoadaptation in intermittent light across the St. Lawrence estuary freshwater-saltwater transition zone. Mar Ecol Prog Ser 110: 283-292

Weinbaum SA, Gressel J, Reisfeld A, Edelman M (1979) Characterization of the 32,000 Dalton chloroplast membrane protein: probing its biological function in Spirodela. Plant Physiol 64:828-832

Wright JC (1959) Limnology of Canyon Ferry Reservoir: phytoplankton standing crop and primary production. Limnol Oceanogr 4:235-245

Yoder JA (1979) Effect of temperature on light-limited growth and chemical composition of Skeletonema costatum (Bacillariophyceae). J Phycol 15:362-370

Submitted: October 24, 2000; Accepted: May 10, 2001

Proofs received from author(s): February 12, 2002 